\title{
ANÁLISE DO DESEMPENHO DE UM MOTOR FLEX-FUEL PARA DIFERENTES RELAÇÕES DE COMPRESSÃO
}

Angelo Maggio Neto ${ }^{1}$, André Vinícius de O. Maggio ${ }^{1}$, Armando Antônio Maria Laganá ${ }^{1}$, Marcos Henrique C. Silva ${ }^{1}$, Marco Isola Naufal ${ }^{2}$, Marco Aurélio Fróes ${ }^{3}$

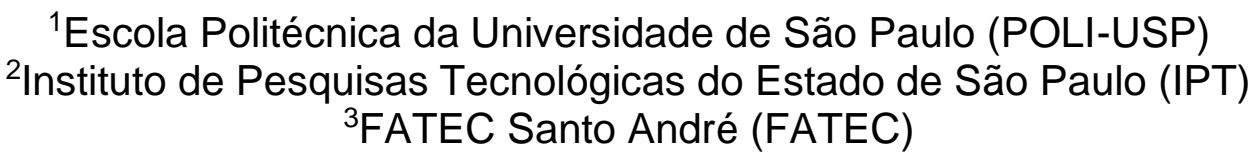

E-mails: angmaggio19@gmail.com, andremaggio@usp.br, armandolagana@terra.com.br,marcoshencarsil@gmail.com,mnaufal@ipt.br, mafroes@uol.com.br

\section{RESUMO}

Motores com relação de compressão variável estão perto da realidade dos veículos comerciais. Com o lançamento da tecnologia da Infinity, os motores monocombustíveis poderão utilizar as vantagens de alterar a taxa de compressão de acordo com a carga solicitada, otimizando o consumo e o desempenho. No caso dos motores flex-fuel, pode-se utilizar esta tecnologia para atuar no regime ideal de cada combustível dado que a gasolina (E22) pode trabalhar dentro de um intervalo de 8,5:1 até 13:1 de valores de taxa de compressão, ao passo que o etanol se concentra na faixa de 10:1 até 14:1. Para o bom funcionamento dos motores flex-fuel, adota-se como característica geométrica do motor uma relação de compressão intermediária entre o etanol e a gasolina, fazendo com que o motor não trabalhe no regime ótimo de nenhum dos combustíveis. Como exemplo, o etanol possui propriedades não exploradas, como a maior resistência a detonação. Nesse contexto, o principal objetivo deste trabalho é verificar o impacto no rendimento térmico e desempenho nos motores com tecnologia flex-fuel, em quatro taxas de compressão, em três diferentes composições: gasolina e27, etanol hidratado e uma composição intermediária.

\section{INTRODUÇÃO}

O presente artigo é resultado de um estudo preliminar a respeito das possibilidades e horizontes que a variação da relação de compressão (VRC) de um motor flex-fuel pode alcançar.

Esta tecnologia está próxima da realidade dos veículos monocombustíveis comerciais [1] e com essa proposta, é possível melhorar a eficiência de qualquer motor de combustão interna alternativo de quatro tempos aumentando a taxa de compressão [4]. Uma outra possibilidade em utilizar esta tecnologia é melhorar o aproveitamento energético dos motores que utilizem mais de um tipo de combustível ou uma mistura entre eles. 
Os motores de combustão à gasolina têm uma faixa da taxa de compressão característica de 8,5:1 até 13,0:1 (para o caso da gasolina utilizada no Brasil que contem adição de etanol E22) enquanto que para motores à etanol esta faixa vai de 10,0:1 até 14,0:1 [3]. Inevitavelmente, os motores flex-fuel atuais possuem relações de compressão intermediárias para ambos os combustíveis, trabalhando em uma condição não ideal, porem permite o seu funcionamento com ambos os combustíveis e misturas feitas entre estes. Isso acarreta na perda do potencial que este motor poderia alcançar se fosse construído com uma taxa de compressão para um determinado combustível. Com a tecnologia VRC, torna-se possível a otimização do desempenho do motor bicombustível utilizando etanol hidratado, gasolina ou suas misturas. Nessa conjuntura, faz-se necessário o estudo do impacto uso das diferentes taxas de compressão aplicadas ao motor flex-fuel.

\section{RELAÇÃO DE COMPRESSÃO}

A relação de compressão de um motor é definida como sendo o número de vezes em que o volume total do cilindro é comprimido no tempo de compressão dentro da câmara de combustão. É uma característica geométrica do motor e é definida como:

$$
\begin{gathered}
R C=\frac{V_{1}}{V_{2}}(1) \\
V_{\text {deslocado }}=V_{1}-V_{2}(2) \\
R C=\frac{V_{\text {deslocado }}+V_{2}}{V_{2}}=\frac{V_{\text {deslocado }}}{V_{2}}+1
\end{gathered}
$$

Onde:

RC é a relação de compressão;

$V_{2}$ é o volume da câmara de combustão $\left[\mathrm{m}^{3}\right]$;

$V_{1}$ é o volume total do cilindro $\left[\mathrm{m}^{3}\right]$;

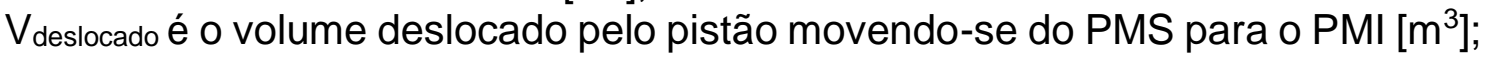

Como descrito em [2], a taxa de compressão influência na eficiência térmica do motor de acordo com a equação a seguir:

$$
\eta=1-\frac{1}{R C \frac{C p}{C v}-1}
$$

Onde:

$\eta$ é a eficiência térmica do motor;

Cp é o calor específico a pressão constante do combustível $\left[\mathrm{J} /\left(\mathrm{Kg}^{*} \mathrm{~K}\right)\right]$;

Cv é o calor específico a volume constante do combustível $\left[\mathrm{J} /\left(\mathrm{Kg}^{*} \mathrm{~K}\right)\right]$;

De acordo com a equação (4), conforme aumenta-se a relação de compressão, aumenta-se a eficiência térmica do motor. 
Pode-se relacionar a eficiência do motor em função do torque como descrito abaixo [5]:

$$
\eta=\frac{T * 4 * \pi}{m_{c o m b} * H}
$$

Onde:

T é o torque $\left[\mathrm{N}^{*} \mathrm{~m}\right]$

mcomb é a massa de combustível [kg];

H é o poder calorífico inferior do combustível [kJ/kg];

Conforme o torque aumenta, a eficiência também aumenta.

Utilizando o modelo de [6] é possível estimar o valor de torque máximo teórico em função da rotação, num dado valor de lambda e de pressão no coletor de admissão. Dessa forma é possível desenvolver a curva de torque máximo teórico por rotação.

\section{MODELO}

Verifica-se que a aproximação da equação (4) não é de fato um bom quantificador, mas sim um indicador da direção rumo a otimização da eficiência térmica do motor. Na prática, o cálculo do rendimento térmico do motor é muito mais complexo, pois depende de diversos fatores como ângulo de ignição, composição e massa do combustível injetado, rotação, relação estequiométrica, temperatura do motor, recirculação dos gases de escape e a pressão no coletor de admissão [6].

O modelo utilizado para quantificar com maior precisão o torque do motor 0 descrito em [6]. Ele consiste em quantificar o torque total produzido de acordo com a quantidade de combustível injetado corrigido pela eficiência de ignição, de rotação, de lambda e perdas por fricção e bombeamento, levando em conta todas as características intrínsecas a geração de torque supracitadas. A equação também leva em conta a correção pela recirculação de gases queimados na câmara de combustão. Contudo o motor utilizado nos testes não conta com esse mecanismo. Portanto esse termo deve ser considerado como 1 para não interferir na equação.

$$
\begin{gathered}
\eta_{e}=e_{c o r}(.)-\frac{V_{d}}{m_{\varphi} \cdot H_{l}} \cdot\left[p_{\text {meog }}(0)+p_{m e 0 f}(.)\right]=\frac{T_{e} \cdot 4 \pi}{m_{\varphi} \cdot H_{l}} \text { (6) } \\
e_{c o r}(.)=e_{\omega_{e}}\left(\omega_{e}, T_{\varphi}, \Upsilon\right) \cdot e_{\lambda}(\lambda, \Upsilon) \cdot e_{\zeta}(\zeta, \Upsilon) \cdot e_{e g r}\left(x_{e g r}\right)+p_{m e 0 g}(0) \cdot K \\
\cdot \frac{\lambda \cdot \sigma_{0} \cdot V_{d}}{H_{l} \cdot m_{\beta, \max }\left(\omega_{e}\right)}
\end{gathered}
$$

Onde:

$\eta_{e}$ - Eficiência térmica do motor [adimensional];

$e_{c o r}($.$) - Eficiência térmica corrigida [adimensional];$

$e_{\omega_{e}}\left(\omega_{e}, T_{\varphi}, Y\right)$ - Correção da eficiência em função da rotação, carga e composição do combustível [adimensional]; 
$e_{\lambda}(\lambda, \Upsilon)$ - Correção da eficiência em função da composição e do fator lambda [adimensional];

$e_{\zeta}(\zeta, Y)$ - Correção da eficiência em função do ângulo de ignição e da composição [adimensional];

$e_{e g r}\left(x_{e g r}\right)$ - Correção da eficiência em função da recirculação de gases queimados [adimensional];

$p_{m e 0 g}(0)$ - Perdas por bombeamento em carga baixa [Pa];

$p_{m e 0 f}($.$) - Perdas por Fricção [Pa];$

$\lambda$ - Relação Ar/Combustível do combustível [adimensional];

$\sigma_{0}$ - Relação estequiométrica teórica para o combustível utilizado [adimensional];

$H_{l}$ - Poder Calorífico Inferior do Combustível [J/Kg];

$m_{\beta, \max }\left(\omega_{e}\right)$ - Massa Gasosa de Saída do Coletor de Admissão do Ciclo [Kg];

$K$ - Fator de Correção [adimensional];

$m_{\varphi}$ - Massa de Combustível [Kg];

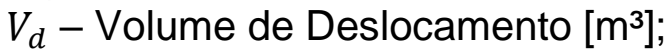

$T_{e}$ - Valor Médio do Torque [N.m];

\section{MÉTODOS EXPERIMENTAIS}

\subsection{DESENVOLVIMENTO}

Foram realizados banco de testes num motor EA111 retirado de um veículo Gol 1.6 modelo 2008, sendo que cada banco é realizado com uma taxa de compressão distinta. Os valores das taxas utilizadas nos bancos de testes são 10,1:1, 11,1:1, 12:1 (Taxa original do motor) e 13,1:1. Para atingir os valores de 10,1:1 e 11,1:1 foram utilizadas 2 juntas de cabeçote modificadas com as espessuras de 2,22 e 1,22 respectivamente. Para a taxa mais elevada, foi utilizado um cabeçote rebaixado em $0,3 \mathrm{~mm}$. Os testes foram executados em cada taxa em 3 composições de combustível, sendo elas gasolina E27, mistura predominantemente etanol hidratado E90 e uma mistura intermediária de gasolina e etanol E60 como está representado esquematicamente pela tabela 1. O teste em si foi utilizado para quantificar em 5 pontos de ângulo de ignição numa dada rotação, pressão do coletor de admissão os valores de torque, temperatura do óleo e o tempo de injeção. Para garantir a estabilidade do motor para que os pontos possam ser identificados e aquisitados com boa acurácia foi utilizado um dinamômetro hidráulico com o motor e uma Unidade de Controle Eletrônico (UCE) programável para controlar as condições necessárias dos testes.

Tabela 1: Testes

\begin{tabular}{|c|c|c|c|c|}
\hline $\begin{array}{l}\text { Relação de } \\
\text { compressão }\end{array}$ & $10,1: 1$ & $11,1: 1$ & 12:1 & $13,3: 1$ \\
\hline \multirow{3}{*}{$\begin{array}{l}\bar{\Phi} \\
\stackrel{D}{\omega} \\
\stackrel{0}{0} \\
\bar{\varepsilon} \\
\mathcal{O}\end{array}$} & E27 & E27 & E27 & E27 \\
\hline & $\mathrm{E} 60$ & E60 & $\mathrm{E} 60$ & E60 \\
\hline & E90 & E90 & E90 & E90 \\
\hline
\end{tabular}




\subsection{IDENTIFICAÇ̃̃O DO FATOR DE CORREÇÃO DA EFICIÊNCIA EM FUNÇÃO DO ÂNNGULO IGNIÇÃO}

O teste consiste em determinar o Torque Líquido Máximo (MBT - Maximum Brake Torque) variando o ângulo de ignição através da Flex ECU medindo o torque líquido com o dinamômetro. Seu comportamento é predito pela equação 8 extraída de [7]. Através da UCE programável deve-se realizar o controle do fator lambda, que deve estar próximo do valor 1 e com o sensor MAP (Manifold Absolute Pressure sensor) determinar a pressão no coletor de admissão. $O$ fator de eficiência devido ao angulo de ignição possui uma relação quadrática entre 0 mesmo e de seu valor ótimo.

$$
e_{\zeta}(\zeta, \Upsilon)=1-k_{\zeta}(\Upsilon) \cdot\left(\zeta-\zeta_{0}\left(\omega_{e}, p_{a d m}, \Upsilon\right)\right)^{2}
$$

Onde:

$k_{\zeta}(\Upsilon)$ : é o mapa do fator do ângulo de ignição com relação a composição;

$\zeta_{0}$ : é o mapa do ângulo ótimo de ignição;

$p_{a d m}$ : Pressão no coletor de admissão no centro de admissão.

Figura 1: Curvas $T_{e}(\zeta)$ para diferentes composições

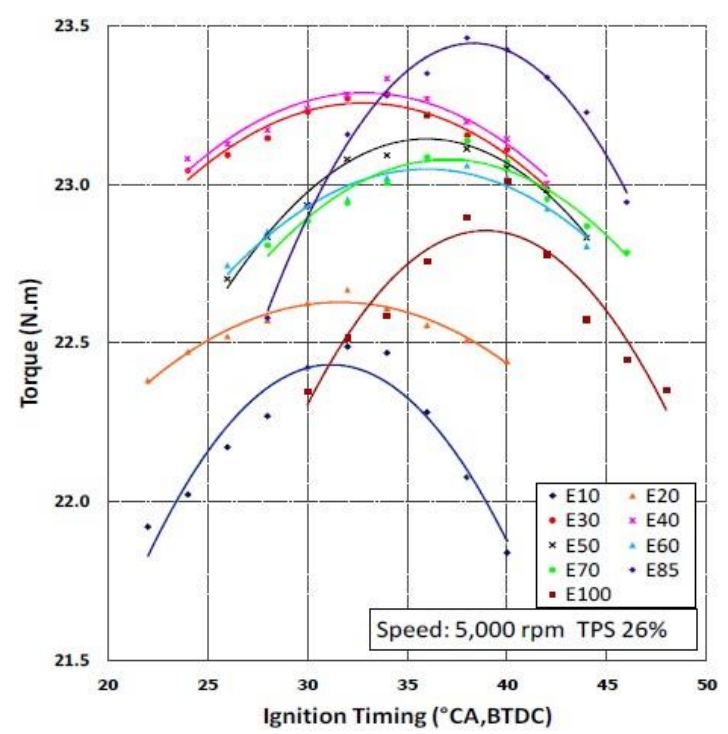

Fonte: [6]

\subsection{IDENTIFICAÇÃO DAS PERDAS POR BOMBEAMENTO}

Esse teste é realizado no dinamômetro onde aquisita-se os valores de pressão no coletor de admissão e de exaustão. A sua diferença corresponde as perdas por bombeamento. Elas são influenciadas pela rotação e pela carga. Variandose uma de cada vez mantendo a outra fixa, é possível elaborar um mapa de três dimensões que corresponde as perdas de bombeamento em função da rotação e das pressões no coletor. 


\subsection{IDENTIFICAÇÃO DO FATOR DE CORREÇÃO DA EFICIÊNCIA DEPENDENTE DA RELAÇÃO AR/COMBUSTÍVEL (fator $\lambda$ )}

O fator $e_{\lambda}(\lambda, \Upsilon)$ procura incluir na modelagem perdas devido à falta ou excesso de oxigênio. $O$ fator $e_{\lambda}(\lambda, \Upsilon)$ é calculado como em [7]:

$$
e_{\lambda}(\lambda, 0)=\left\{\begin{array}{lr}
\gamma_{1} \cdot \lambda-\gamma_{0} & \text { para } \lambda_{\min }<\lambda<1 \\
e_{\lambda, 1}+\left(1-e_{\lambda, 1}\right) \cdot \sin \left(\frac{\lambda-\lambda_{1}}{1-\lambda_{1}}\right) & \text { para } \lambda_{1}<\lambda<\lambda_{2} \\
1 & \text { para } \lambda_{2}<\lambda<\lambda_{\max }
\end{array}\right.
$$

Onde:

$e_{\lambda, 1}=\gamma_{1} \cdot \lambda-\gamma_{0}$

$\lambda_{1}=0.95$

$\lambda_{2}=1.0285$

$\gamma_{1}, \gamma_{0}$ são parâmetros a serem identificados;

Os limites $\lambda_{\min }$ e $\lambda_{\max }$ são os pontos nos quais ocorre falhas de ignição.

Os parâmetros $\gamma_{1}$ e $\gamma_{0}$ serão identificados como uma função de primeiro grau com relação à composição do combustível na faixa de E27 a E100. Considerase que a variação em função da composição é pequena, como visto na figura 2 , pode-se desprezar a influência da composição para $e_{\lambda}(\lambda, \Upsilon)$.

Figura 2: Eficiência da combustão em função da razão equivalente combustível/ar para composição variada.

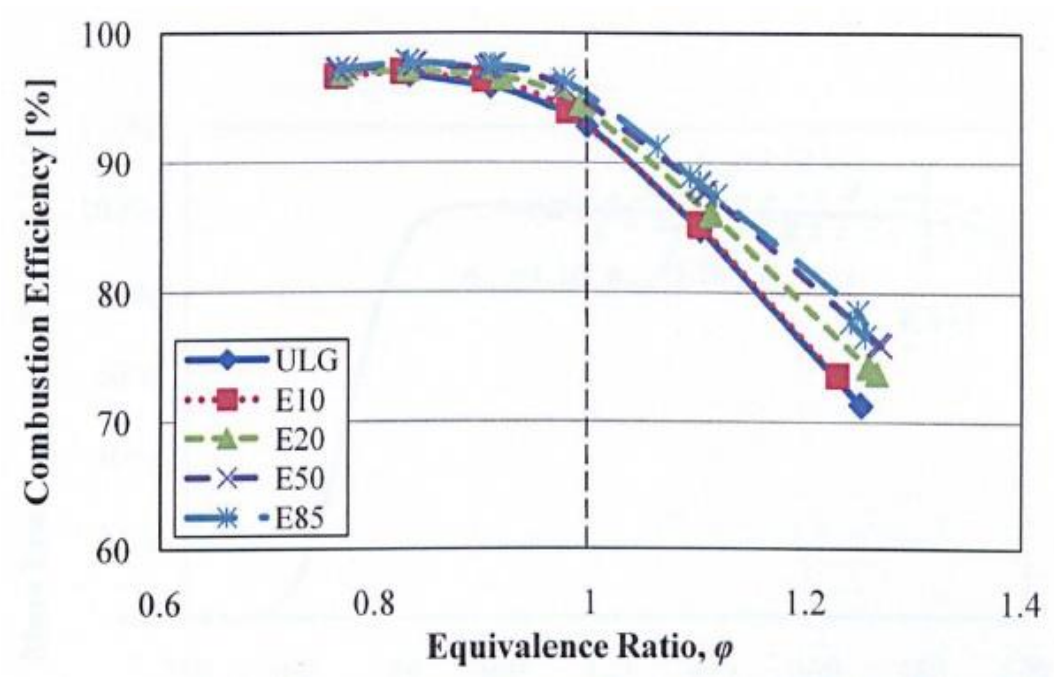

Fonte: [6]

\subsection{IDENTIFICAÇÃO DO FATOR DE CORREÇÃO DA EFICIÊNCIA EM FUNÇÃO DA ROTAÇÃO.}

Após identificar os fatores anteriores, deve-se isolar o fator $e_{\omega_{e}}\left(\omega_{e}, T_{\varphi}, \Upsilon\right)$ na equação e calculá-lo a partir dos outros. Como resultado tem-se um mapa em função de cada rotação e da carga onde foi realizado os demais testes. A carga é incluída devido a sua influência no rendimento térmico do motor [7]. 


\section{RESULTADOS E DISCUSSÕES}

Os resultados encontrados estão representados nos gráficos a seguir.

Figura 3: Torque x Rotação

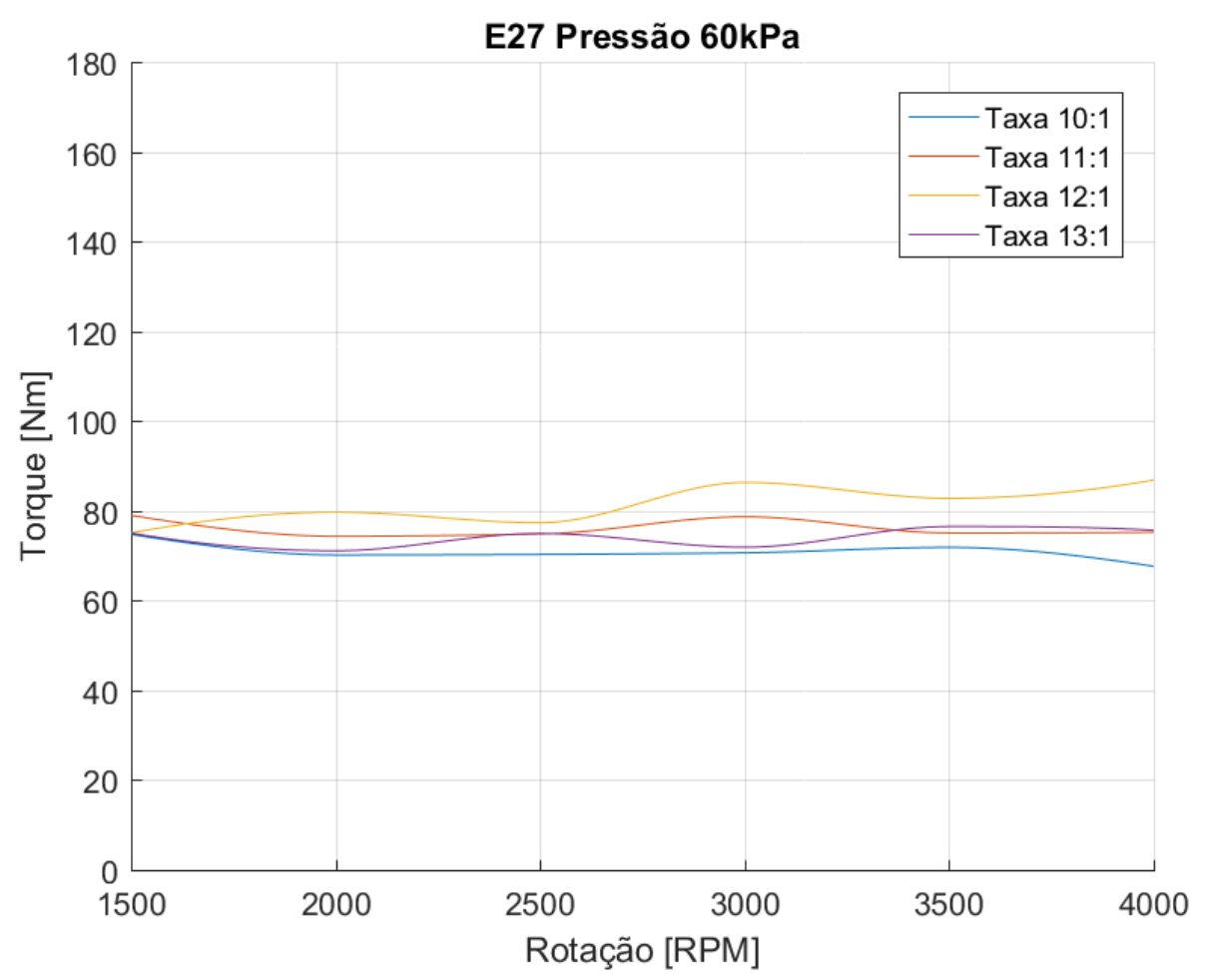

Figura 4: Torque x Rotação

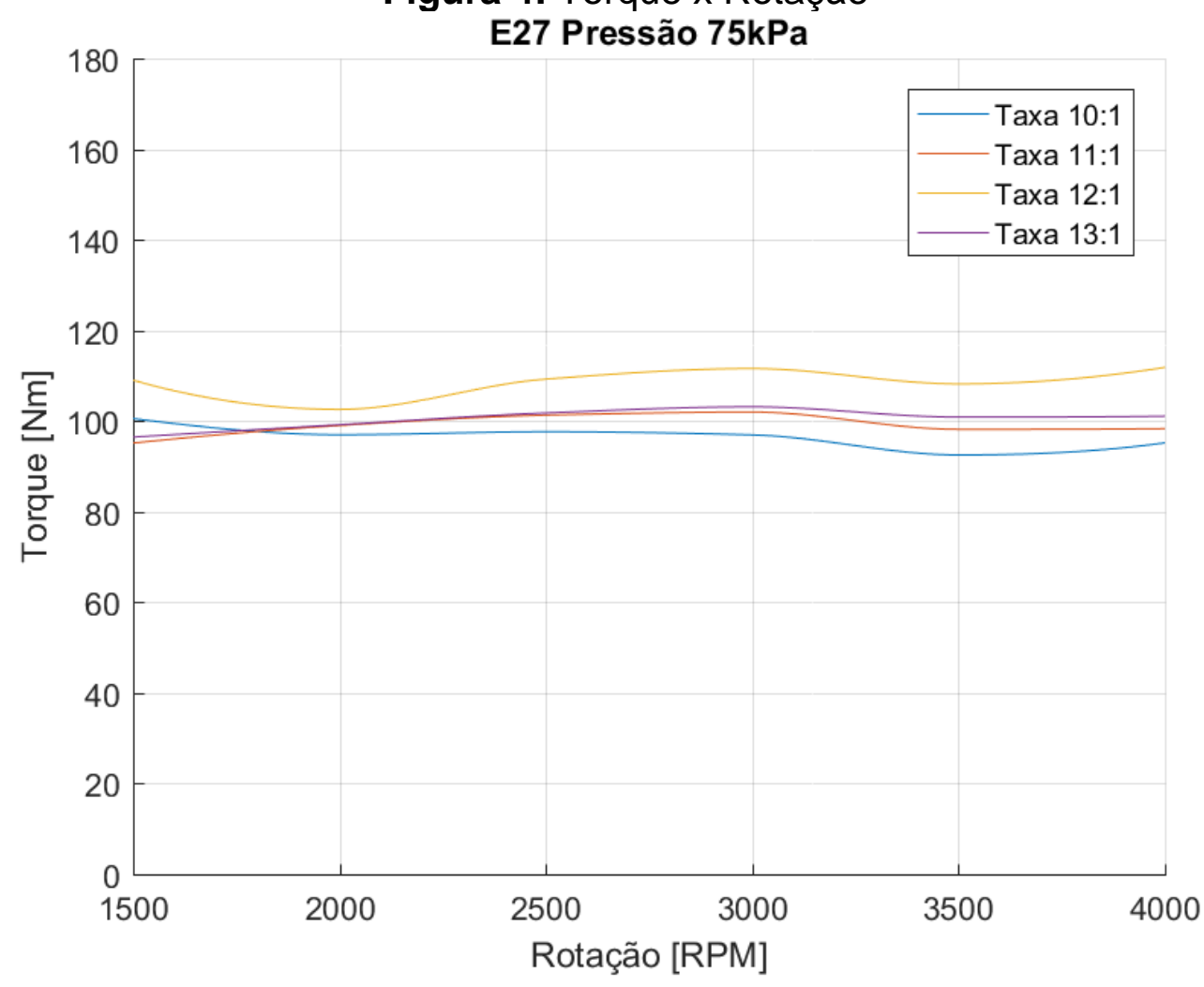


Figura 5: Torque x Rotação

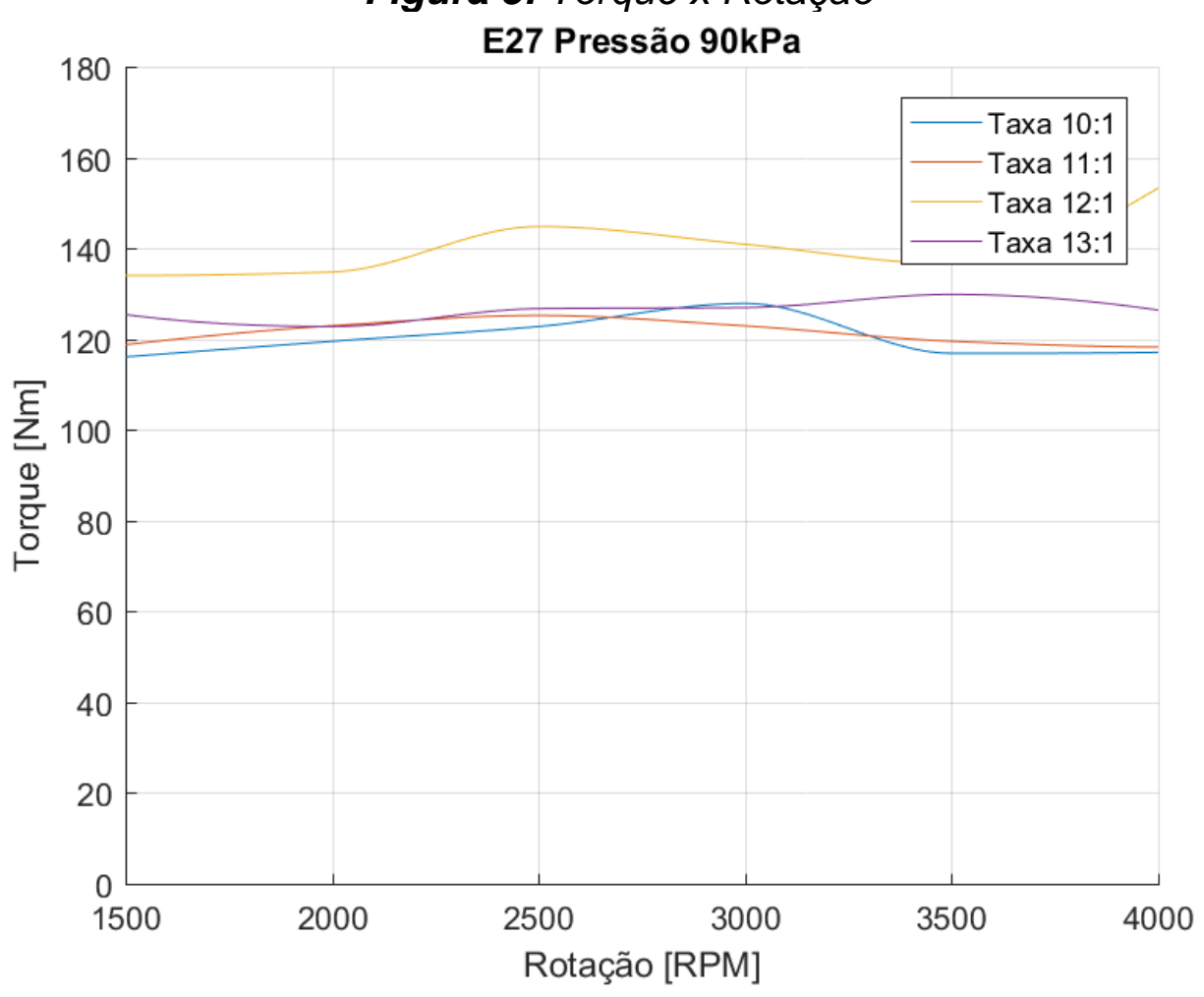

Figura 6: Torque x Rotação

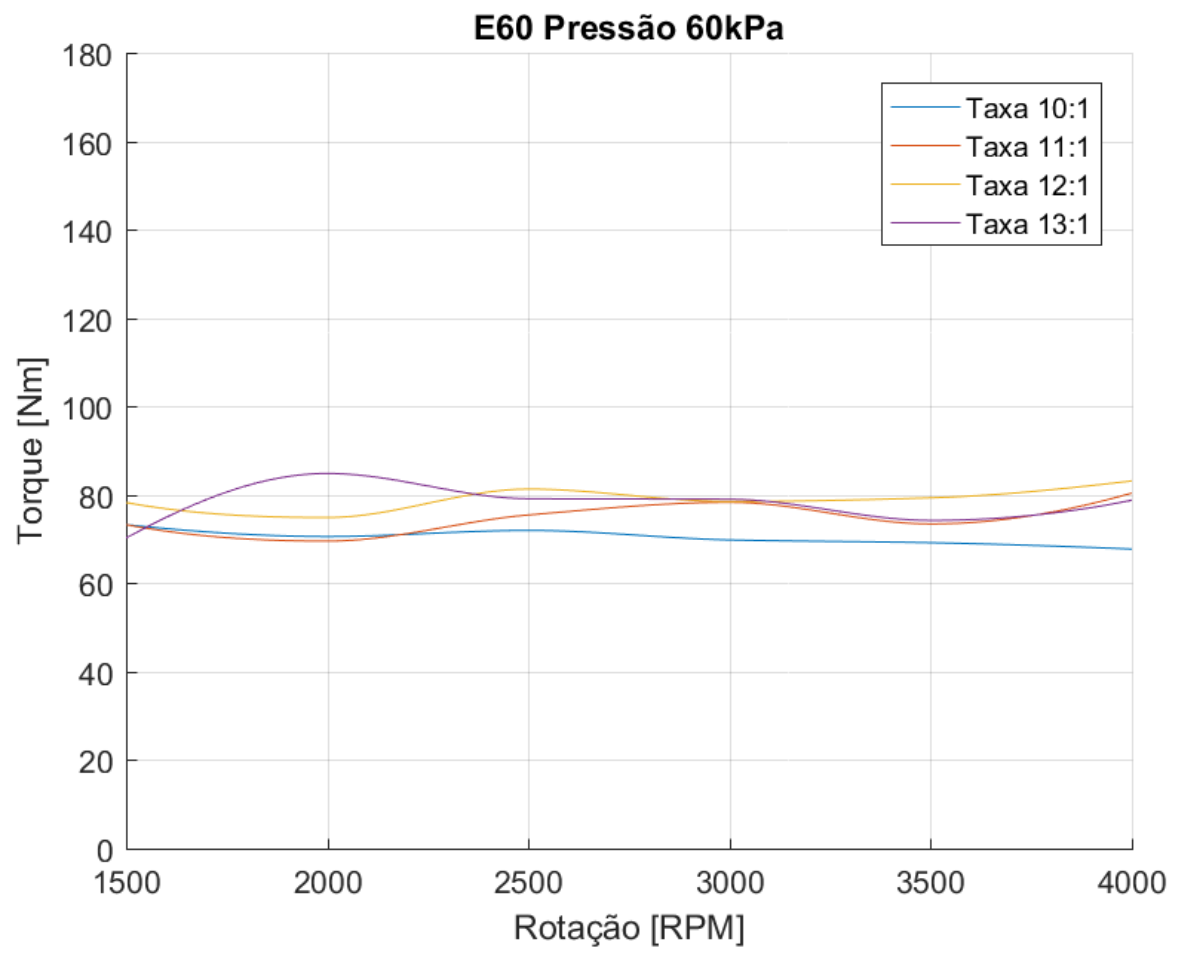


Figura 7: Torque x Rotação

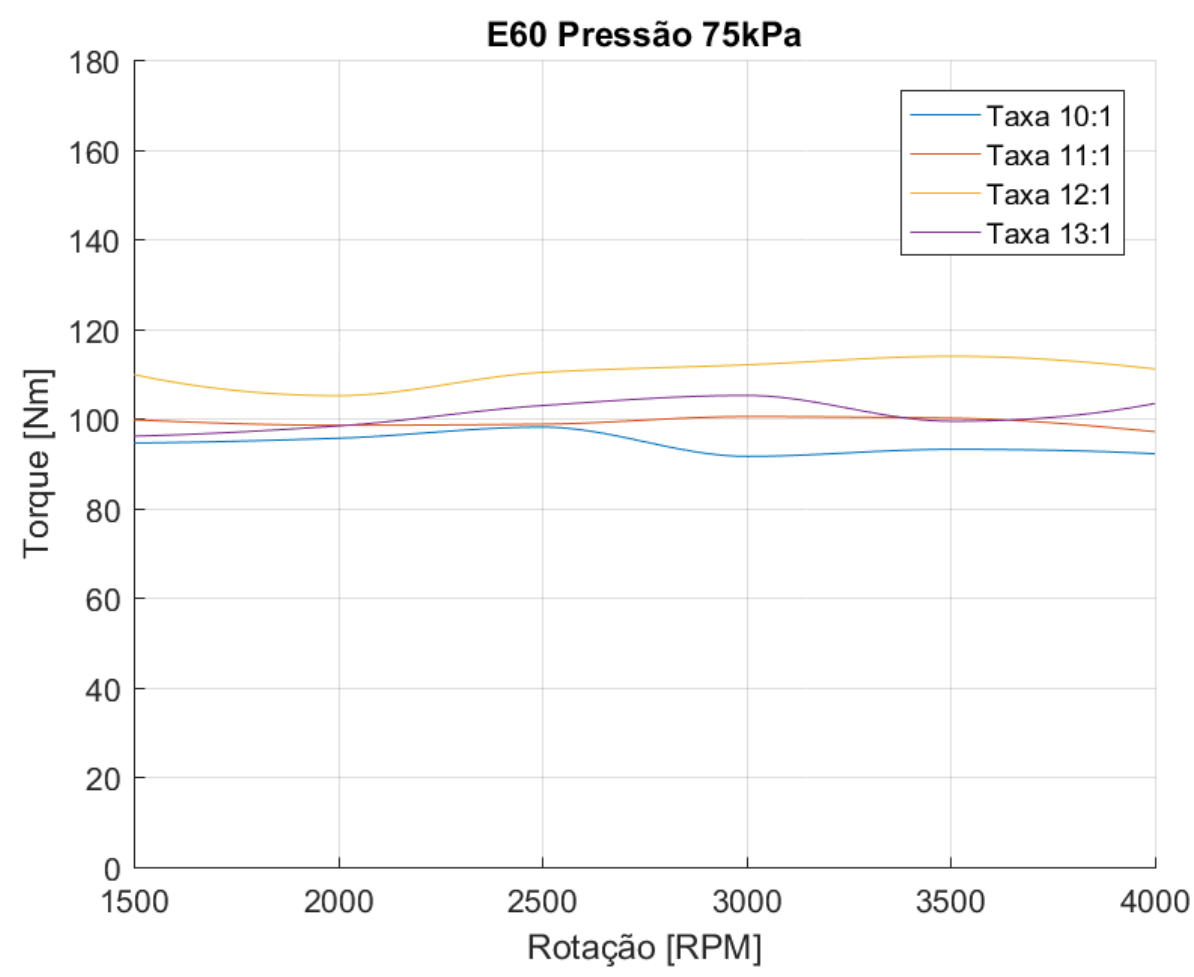

Figura 8: Torque x Rotação

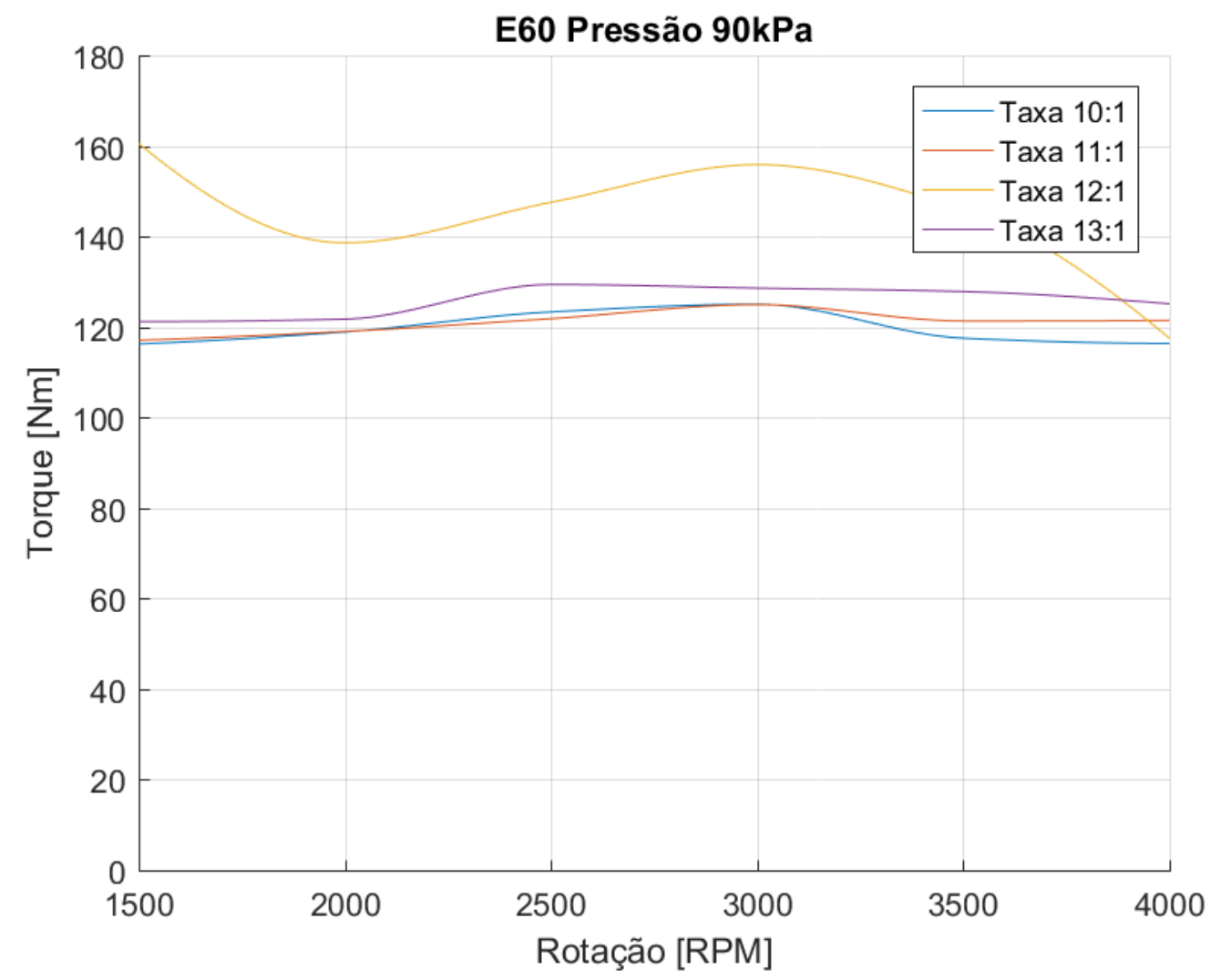


Figura 9: Torque x Rotação

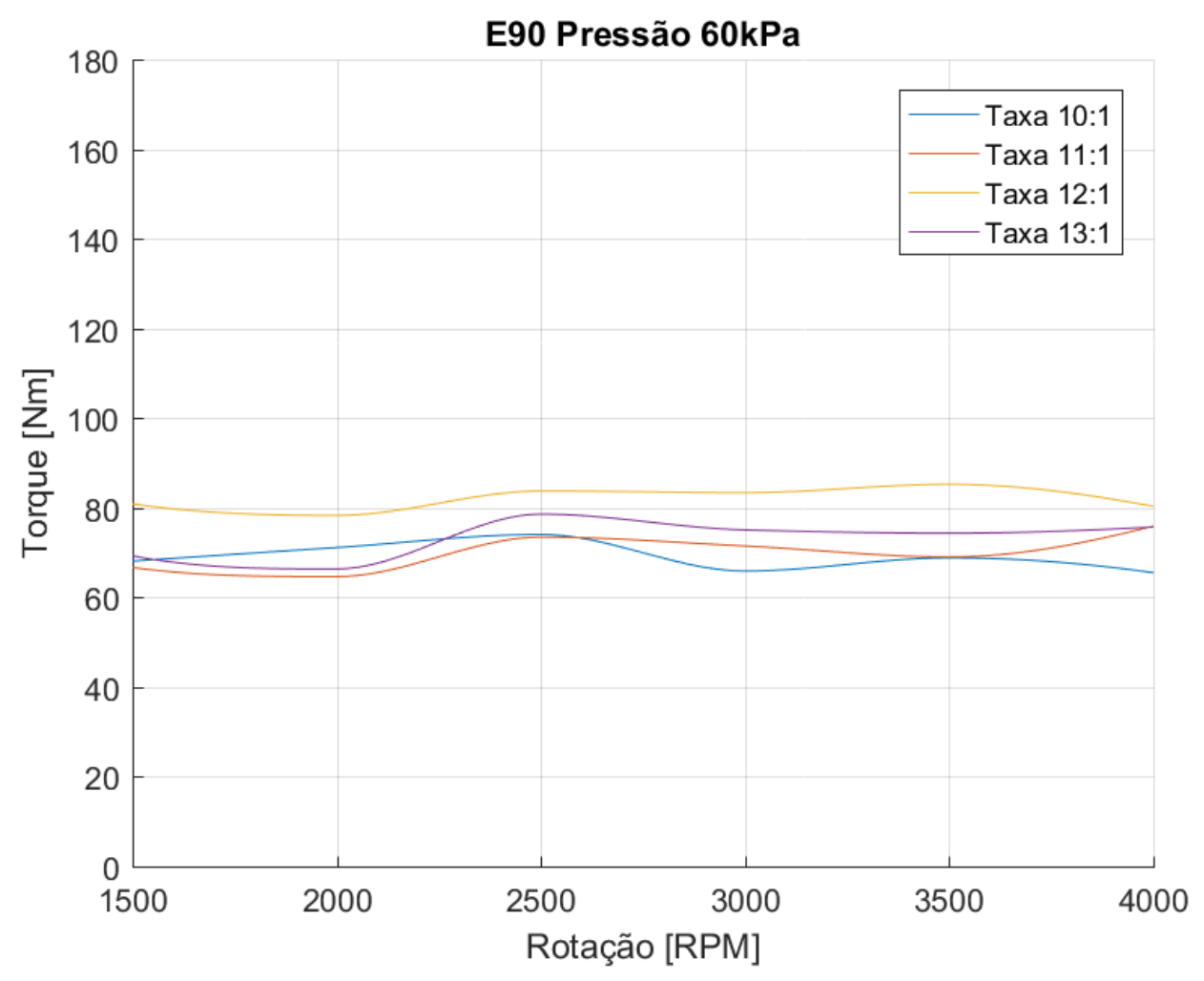

Figura 10: Torque x Rotação

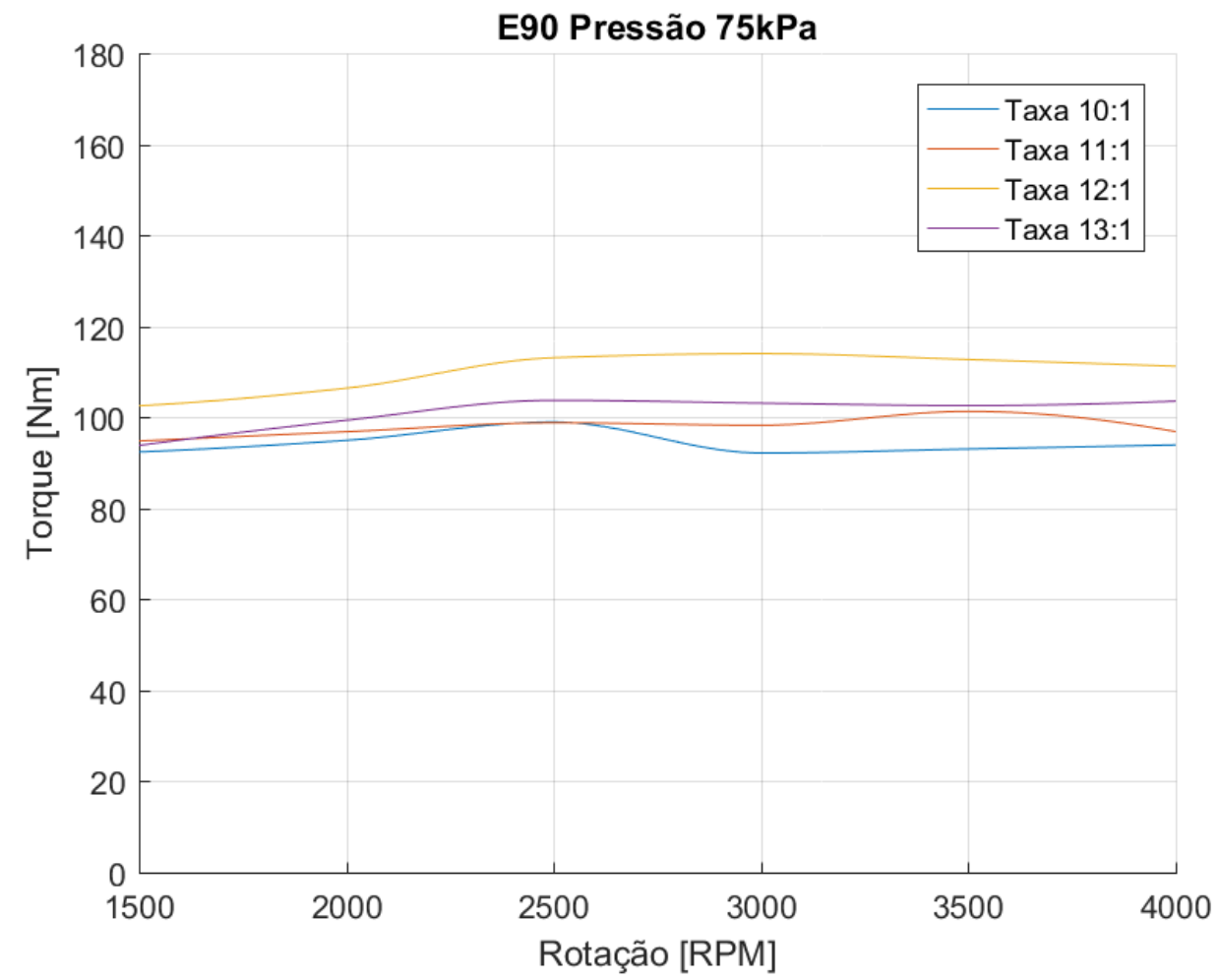


Figura 11: Torque x Rotação

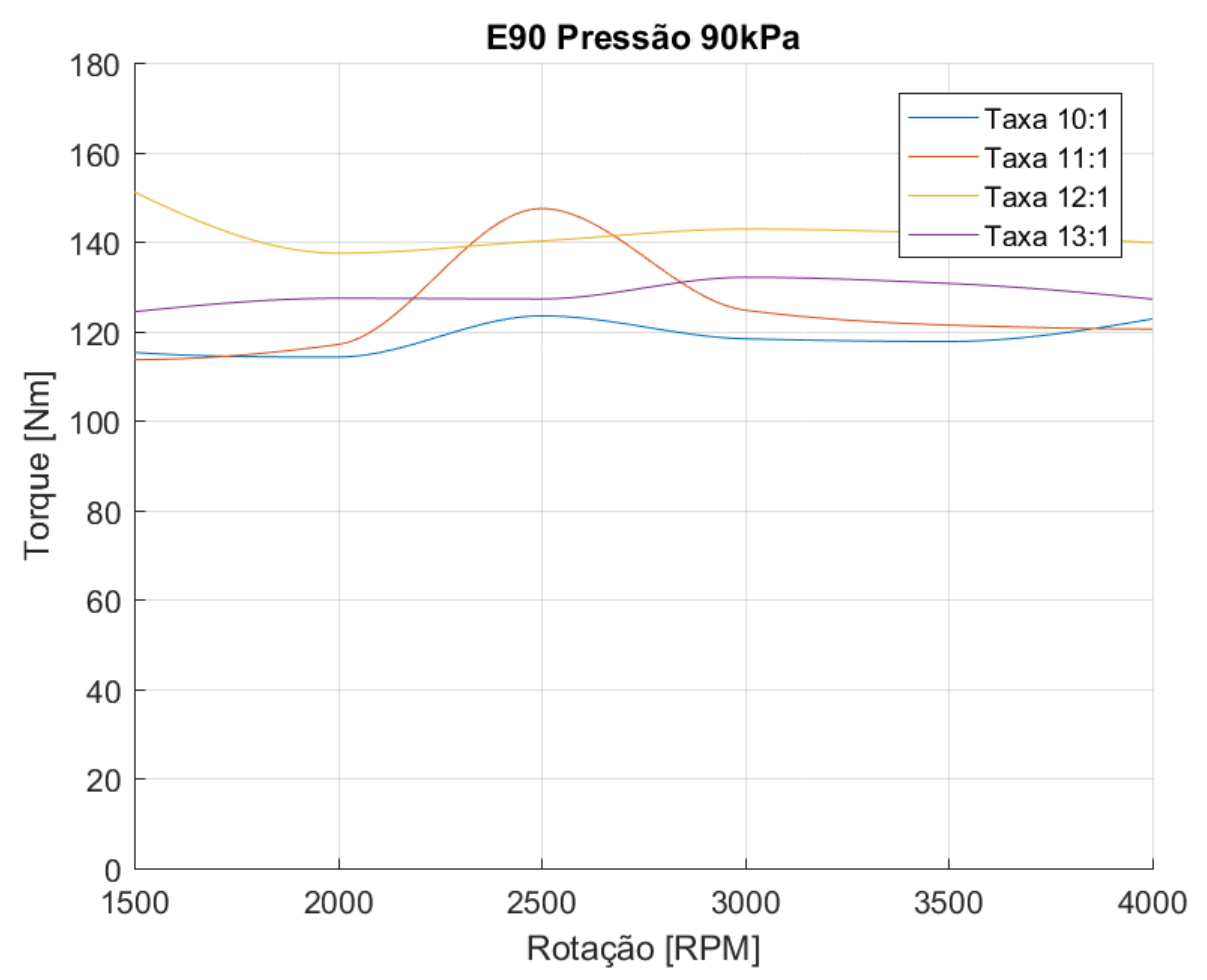

Figura 12: Eficiência Térmica x Rotação

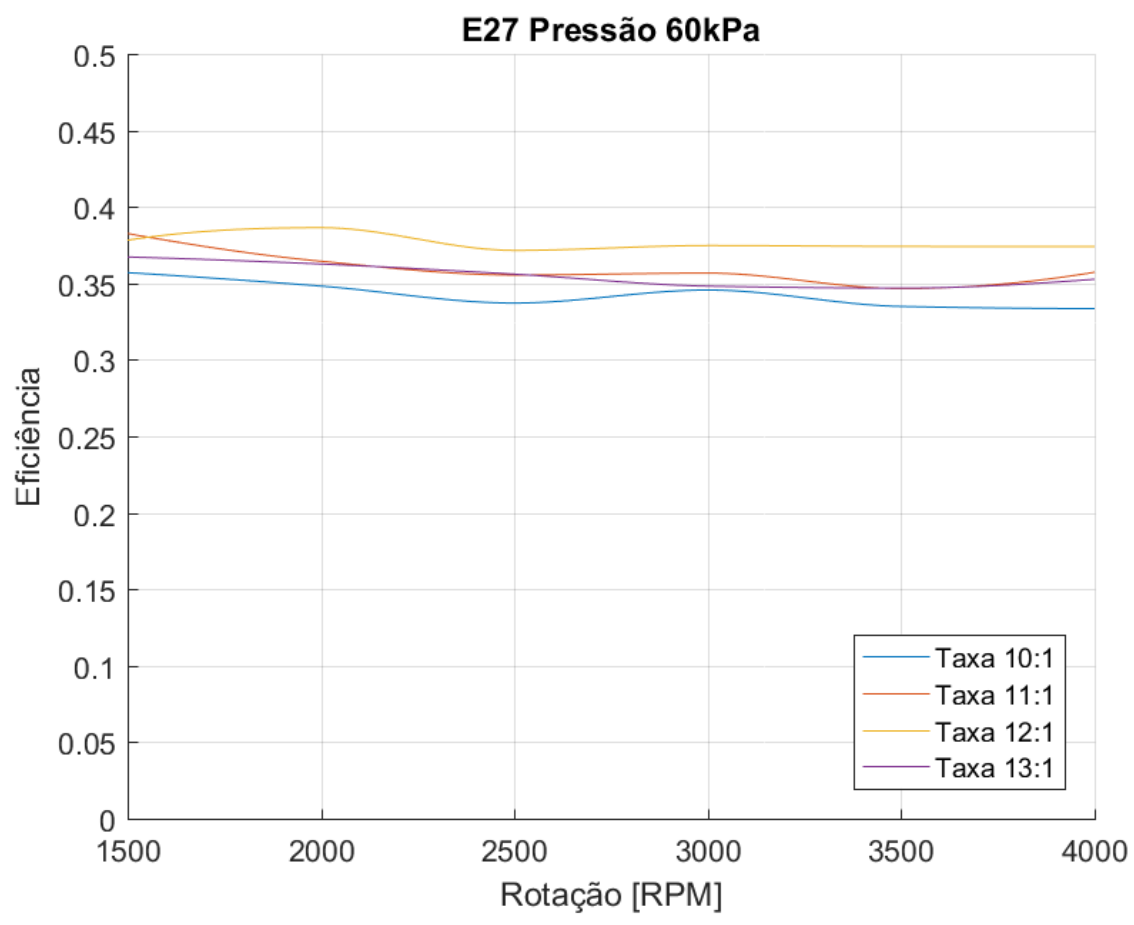


Figura 13: Eficiência Térmica $x$ Rotação

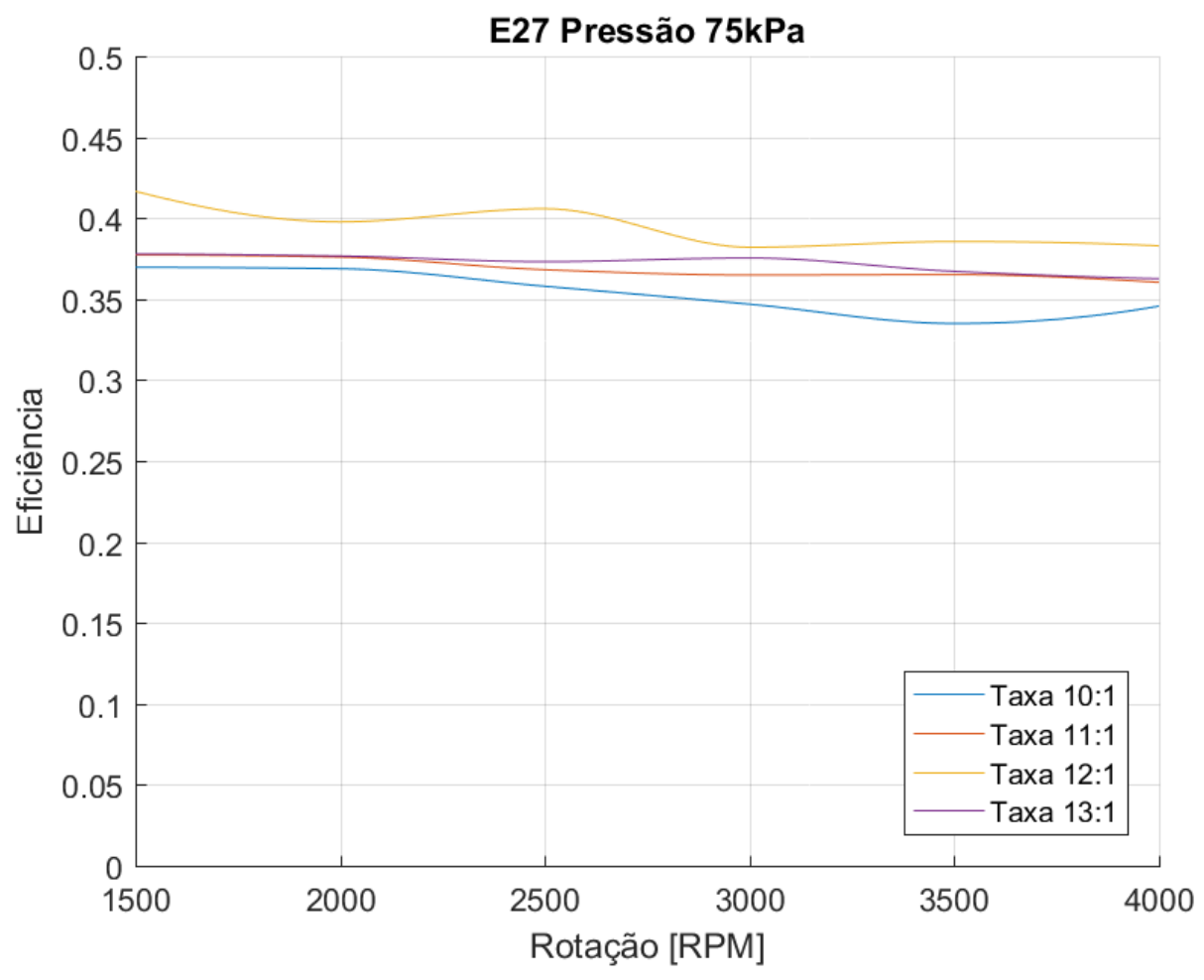

Figura 14: Eficiência Térmica x Rotação

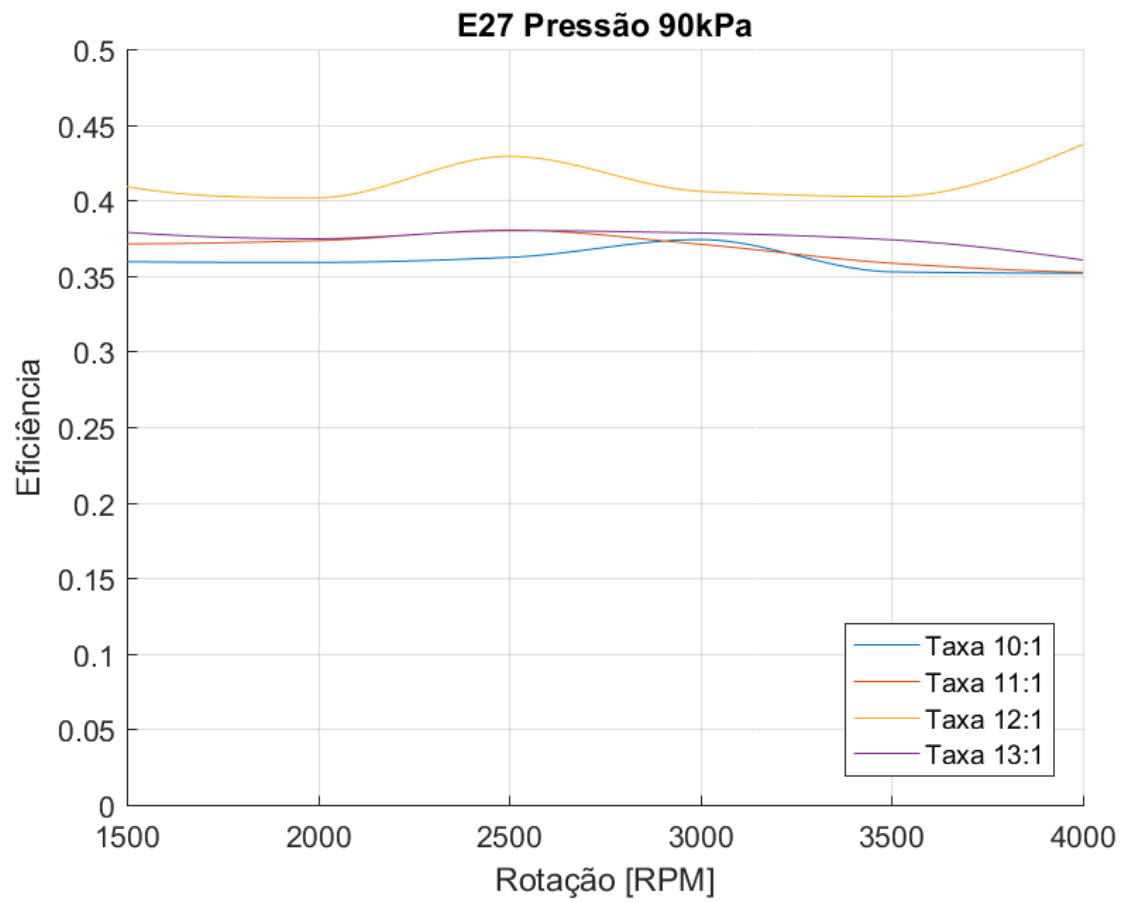


Figura 15: Eficiência Térmica x Rotação

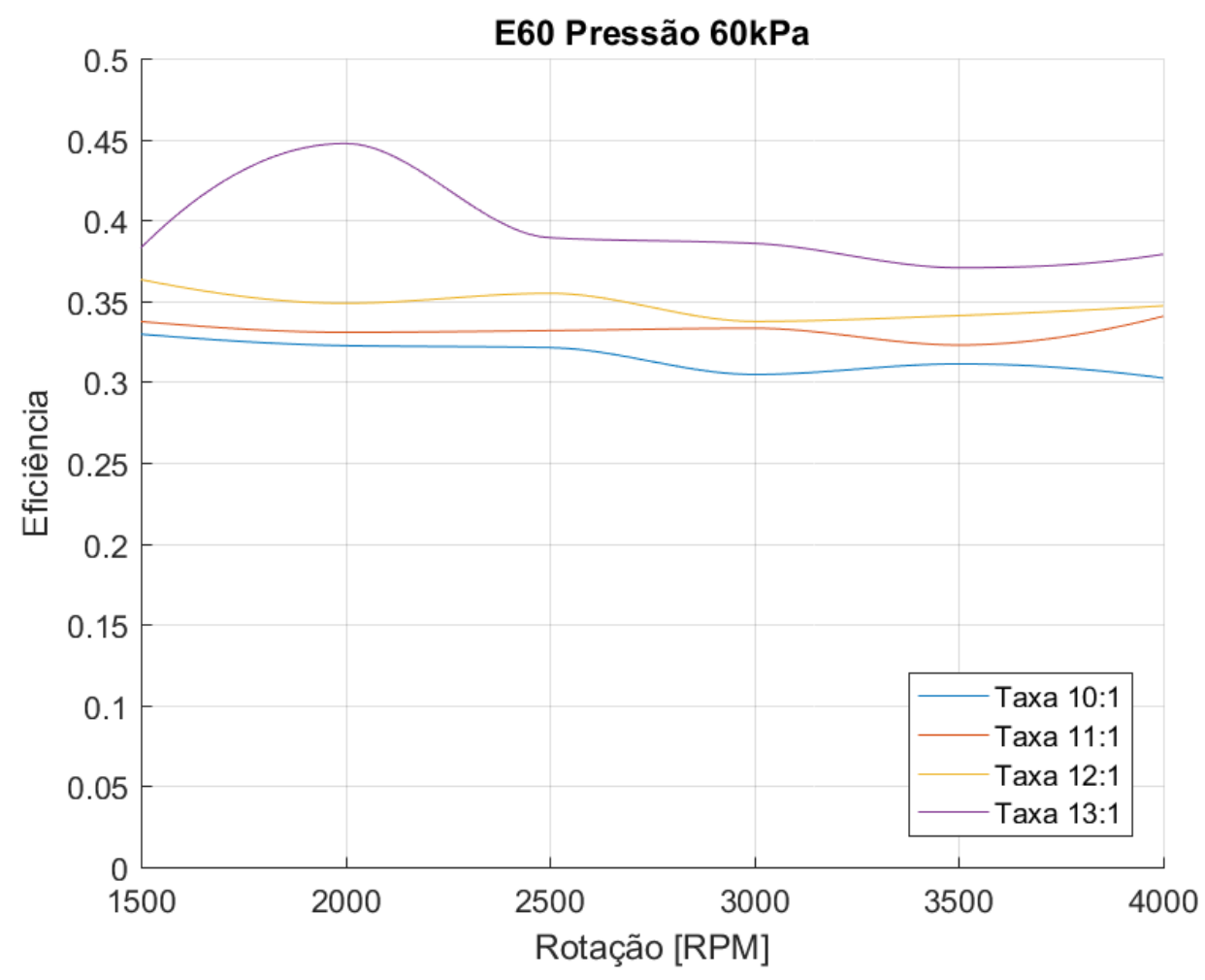

Figura 16: Eficiência Térmica x Rotação

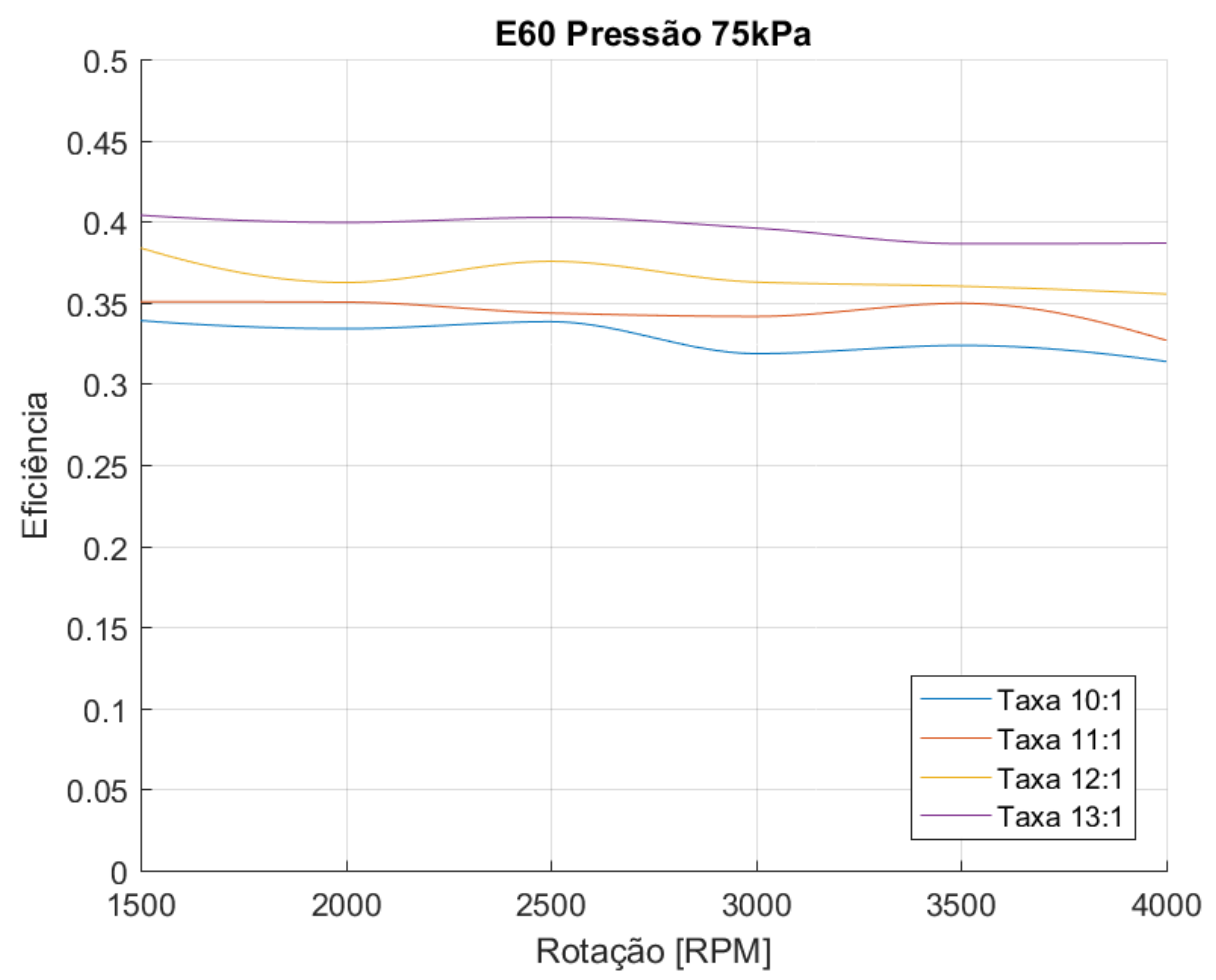


Figura 17: Eficiência Térmica x Rotação

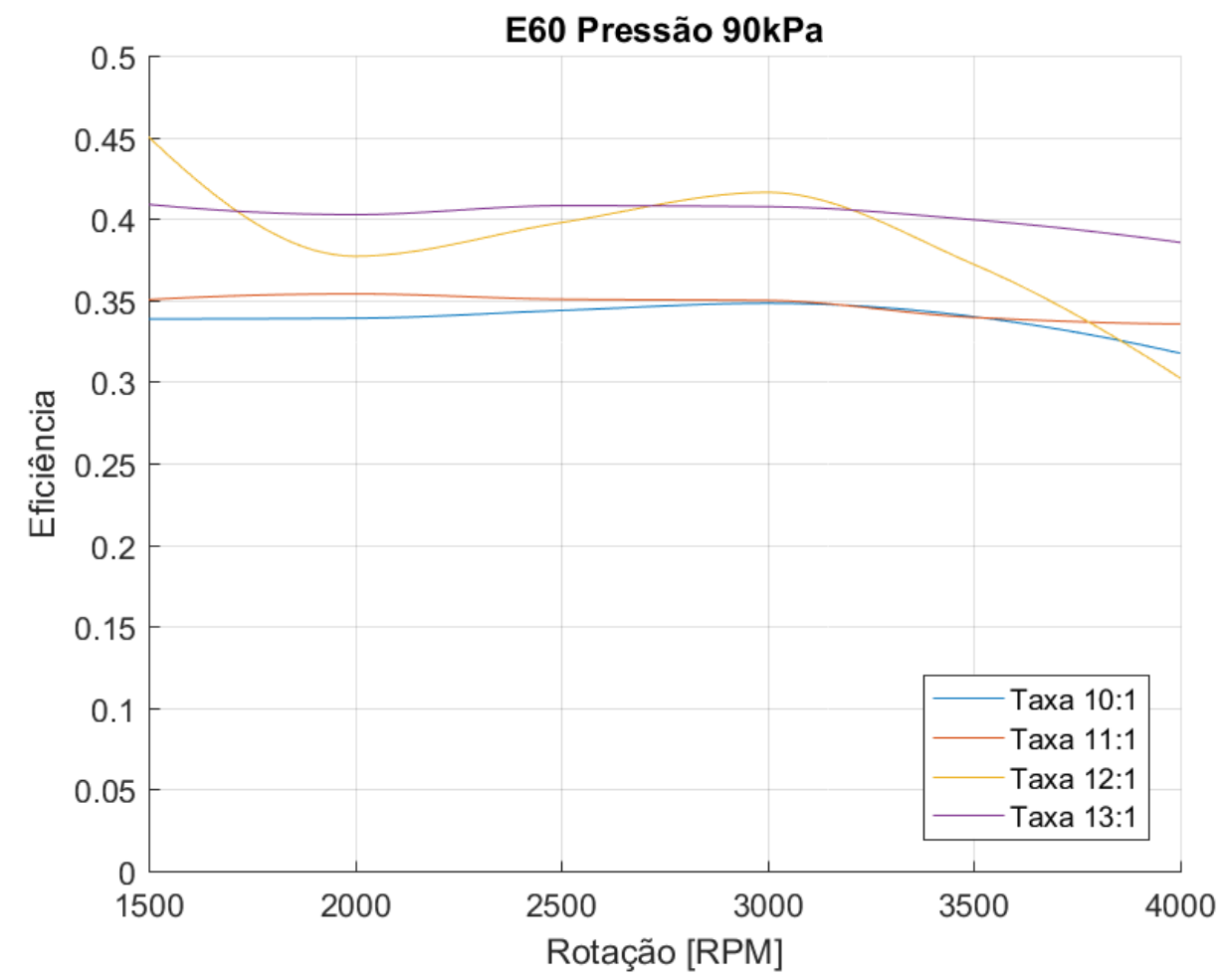

Figura 18: Eficiência Térmica x Rotação

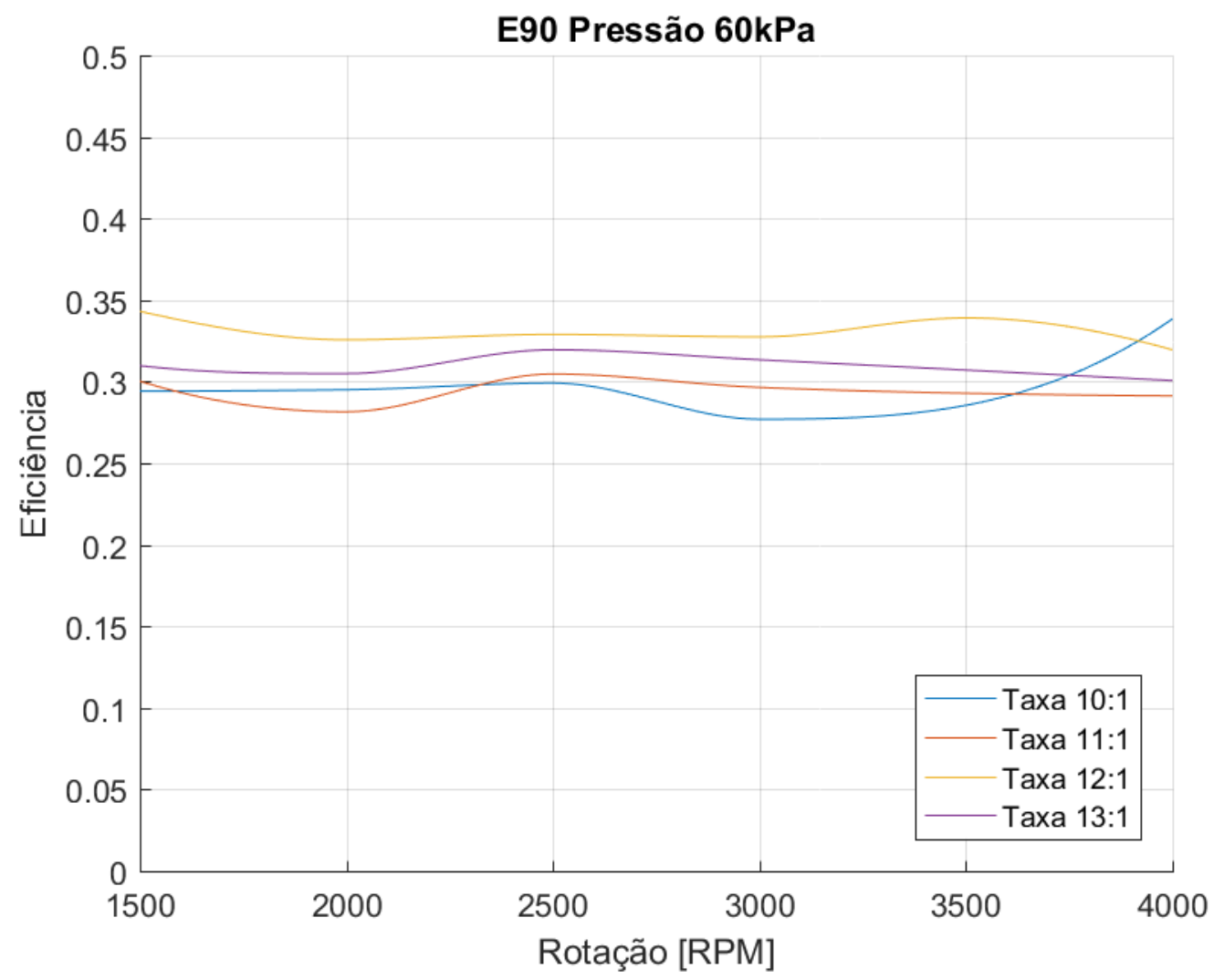


Figura 19: Eficiência Térmica x Rotação

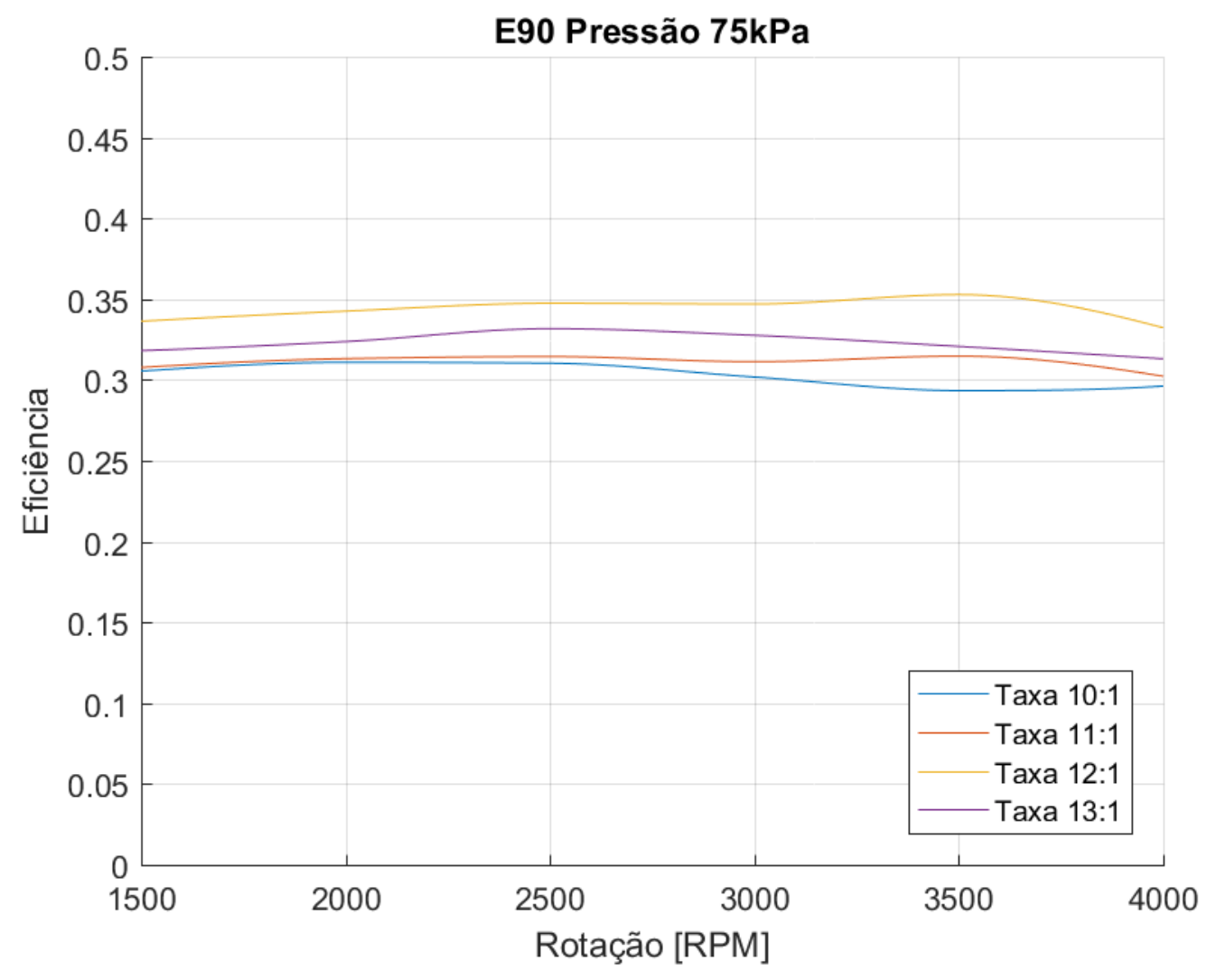

Figura 20: Eficiência Térmica x Rotação

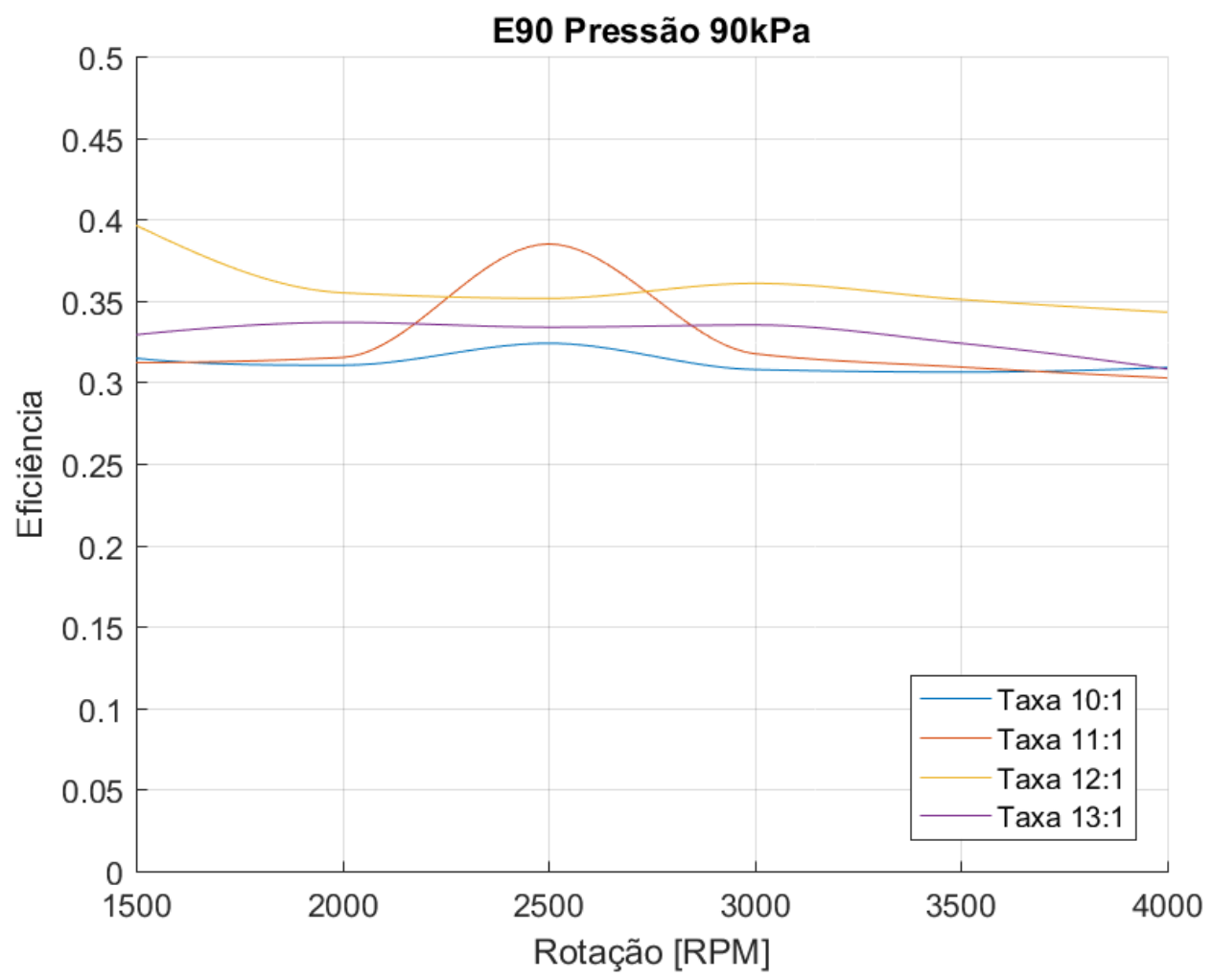


Como pode ser observado existem dois grupos de gráficos, os da eficiência térmica por rotação e de torque por rotação. Há a predominância de maiores valores de torque para as taxas de 12:1 inclusive nas composições de etanol E90, contrariando a teoria descrita na seção 1 . A predominância da eficiência na taxa de 13,3:1 estão nos gráficos de composição E60, em contrapartida, nas demais composições, a taxa 12:1 predomina. As curvas dos gráficos diferenciam-se sem haver qualquer padrão. Como foi possível observar uma melhora na eficiência para a composição intermediaria E60. O estudo preliminar também sugere que é interessante utilizar taxas de compressão mais elevadas a fim de observar se tal comportamento como observado para o caso do E60 não se repete para o caso do E90. Outro ponto a ser explorado em trabalhos futuros é a inclusão limiar da ocorrência do knock que limita o avanço do angulo de ignição devido a necessidade de evitar o fenômeno da detonação principalmente para misturas com maior percentual de gasolina.

\section{CONCLUSÃO}

Estes são gráficos debruçados estritamente na teoria já descrita não considerando restrições do ângulo de ignição a fim de evitar o knock, pois o modelo utiliza o MBT sem a correção da ocorrência de knock no fator de correção do avanço do ângulo de ignição. Como é visto em [4] a limitação imposta pelo knock (condição que deve ser evitada para preservar e garantir o bom funcionamento do motor) impacta diretamente na geração de torque e consequentemente da eficiência térmica do motor de forma significativa. Portanto num futuro trabalho a correção pela ocorrência do knock deve ser incorporada. Portanto, o modelo carece de melhorias bem como mais pontos para um melhor resultado.

\section{BIBLIOGRAFIA}

[1] Kendall, J. (03 de Outubro de 2016). Nissan unveils 2018 production variable-compression-ratio ICE. Fonte: SAE International: https://www.sae.org/news/2016/10/nissan-unveils-2018-productionvariable-compression-ratio-ice

[2] Heywood, J. B. (1988). Internal Combustion Engines Fundamentals. USA: McGraw-Hill.

[3] Nilsson, Y. (2007). Modelling for Fuel Optimal Control of a Variable Compression Engine. Linkoping - Suécia: Linkoping University.

[4] Brunetti, F. (2012). Motores de Combustão Interna (1 ${ }^{a}$ Edição ed., Vol. Volume 1). São Paulo: Blucher.

[5] Guzzella, L., \& Onder, C. H. (2010). Introduction to Modeling and Control of Internal Combustion Engine System. Zurich - Suiça: Springer.

[6] Silva, M. H., \& Laganá, A. A. (setembro de 2017). Modelagem de Torque para Motores com Tecnologia Flex. XXV Simpósio Internacional de Engenharia Automotiva . São Paulo, SP.

[7] Silva, M. H. (2018). Modelagem de Motores a Combustão Interna com Tecnologia Flex. Dissertação de Mestrado, São Paulo: USP. 